\title{
Endovascular treatment of ruptured thoracic aortic aneurysms
}

\author{
Pierre Alric, MD, and Charles Henri Marty-Ané, MD, Montpellier, France
}

A

$\mathrm{n}$ open surgical procedure with prosthetic vascular graft repair is the conventional treatment for patients with thoracic aortic aneurysm (TAA), although such procedures carry a substantial operative risk related to the major thoracic approach, the use of cardiopulmonary bypass, and such major potential postoperative complications as paraplegia or renal failure. The natural history of TAA in a high proportion of untreated patients is rupture, which invariably results in death. In contrast to the improving results of elective surgery, surgical treatment of ruptured TAA remains technically challenging and gives dismal results, with a mortality of more than $50 \% .^{1,2}$ Recently, several authors have reported the successful treatment of TAA with the implantation of stent grafts. ${ }^{3-5}$ We report the cases of 7 patients with ruptured TAAs successfully excluded with endoluminal stent grafts.

\section{Patients and Methods}

Six men and 1 woman, aged 61 to 85 years old (mean $76.4 \pm 7.4$ years) were evaluated as being at high operative risk by both the

From the Department of Thoracic and Vascular Surgery, Hospital Arnaud de Villeneuve, Montpellier, France.

Received for publication Dec 14, 2001; accepted for publication Dec 26, 2001.

Address for reprints: Pierre Alric, MD, Queen's Medical Centre, Nottingham University Hospital, NHS Trust, Department of Vascular Surgery, Floor E-West Block, Nottingham NG7 2UH, United Kingdom (E-mail: pierrealric@hotmail.com).

J Thorac Cardiovasc Surg 2002;124:180-2

Copyright $\odot 2002$ by The American Association for Thoracic Surgery

$0022-5223 / 2002 \$ 35.00+0 \quad \mathbf{1 2 / 5 4 / 1 2 2 5 3 7}$

doi: $10.1067 / \mathrm{mtc} .2002 .122537$ surgical and anesthesiology teams. All patients had severe comorbidities and were in American Society of Anesthesiologists class III $(n=4)$ or class IV $(\mathrm{n}=3)$. The mean interval between the onset of

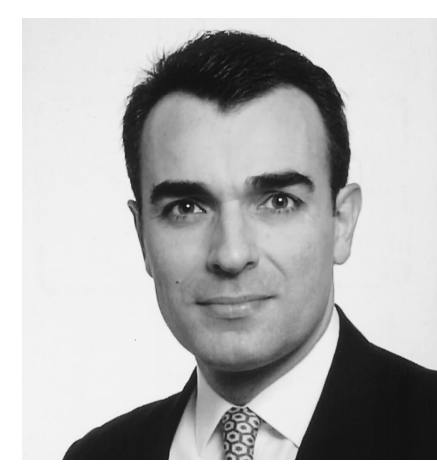

Dr Alric symptoms and the endovascular repair was $37.3 \pm 29.8$ hours, and all patients were treated within 100 hours.

Endovascular treatment was chosen according to appropriate morphologic criteria: proximal and distal neck of healthy aorta at least $20 \mathrm{~mm}$ in length and not more than $38 \mathrm{~mm}$ in diameter, absence of thrombus in the landing zones, and absence of marked tortuosity or stenosis of the aortoiliac arteries. The initial clinical presentations were thoracic pain $(n=6)$, transient collapse $(n=$ $5)$, and irreversible collapse after fluid perfusion $(n=2)$. The last patient had a massive hemoptysis related to aortobronchial fistula (this occurred 1 year after a left superior lobectomy with simultaneous surgical wrapping of a saccular TAA). Six patients underwent an emergency computed tomographic scan. We opted for an emergency magnetic resonance angiography in 1 case because of renal failure (Figure 1). In 2 cases, severe collapse precluded preoperative angiography, which instead was performed intraoperatively, just before stent-graft placement (Figure 2). The maximal aneurysmal diameter ranged from 40 to $90 \mathrm{~mm}$. The aneurysmal locations were the proximal descending thoracic aorta $(n=3)$, the distal descending aorta $(n=3)$, and the entire descending aorta $(\mathrm{n}=1)$. The delay for availability of the stent graft varied from 6 to 24 hours. The Excluder stent graft (W.L. Gore \& Associates, Sunnyvale, Calif) was used in 6 cases and the Talent stent graft (Medtronic AVE, Santa Rosa, California) was used in 1 case. The oversizing of the endoprosthesis relative to aortic diameter ranged from $10 \%$ to $15 \%$. After a common femoral artery approach with 

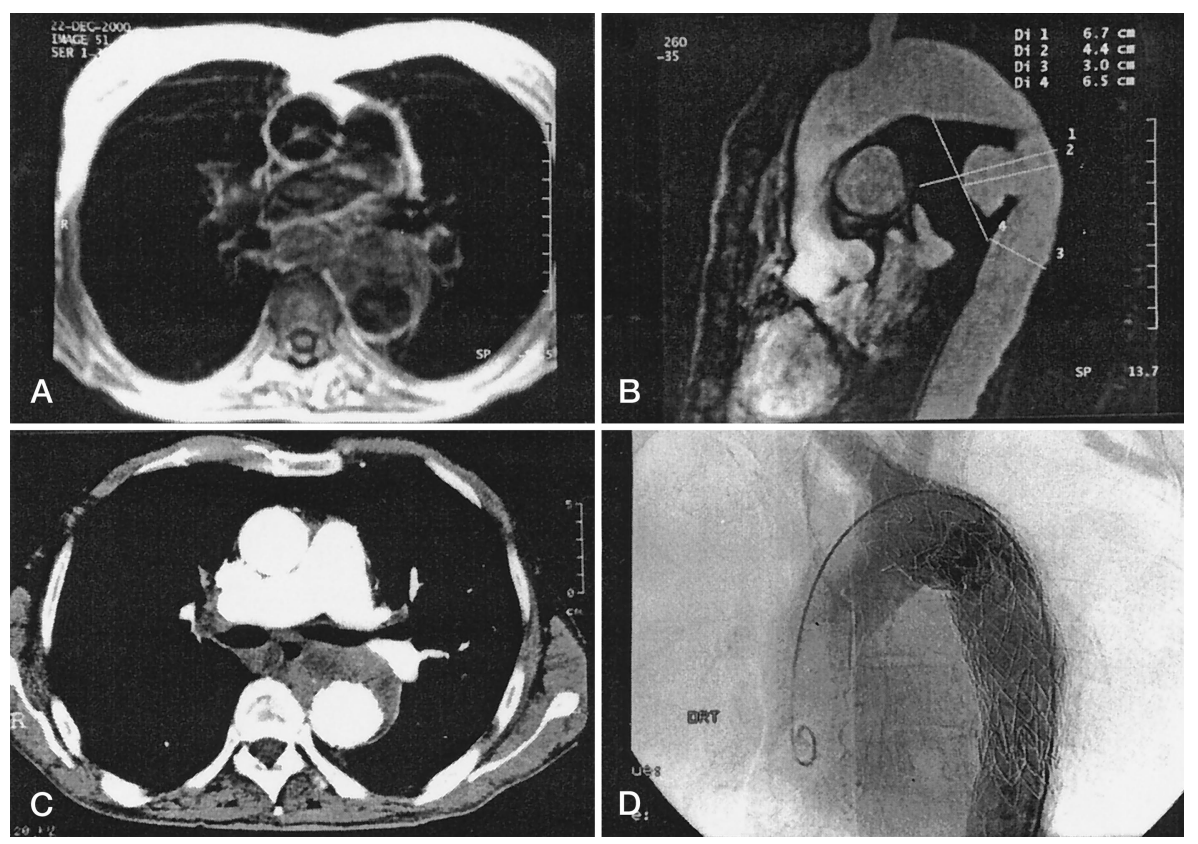

Figure 1. Ruptured aneurysm of proximal descending aorta in 75-year-old man with renal failure, arteritis, atrial fibrillation and arterial hypertension. A, Contained aortic rupture with mediastinal hematoma on preoperative magnetic resonance angiography. $B$, Preoperative magnetic resonance angiography confirming rupture of proximal descending aorta. C, Exclusion of rupture with Excluder stent graft on postoperative computed tomographic scan. D, No evidence of perigraft leak on postoperative angiography 3 months after endovascular repair.
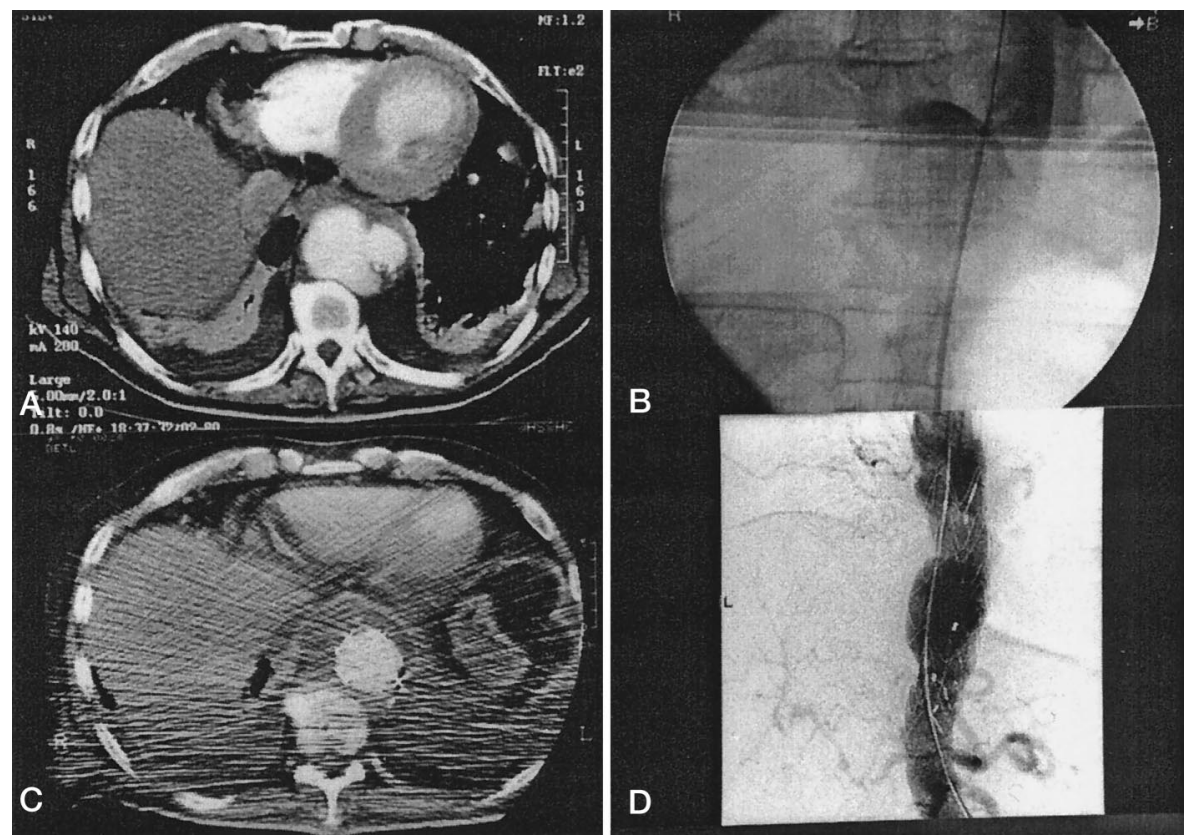

Figure 2. Ruptured aneurysm of distal descending aorta in 75-year-old man with chronic obstructive pulmonary disease, cardiac failure, atrial fibrillation, and arterial hypertension. A, Contrast extravasation from ruptured aorta between crura of diaphragm on preoperative computed tomographic scan. B, Intraoperative angiography showing contained rupture of distal descending aorta. C, Immediate postoperative computed tomographic scan demonstrating exclusion of aneurysm with Talent stent graft. D, Stent graft appears well positioned just above celiac axis, with no evidence of perigraft leak on postoperative angiography 1 month after endovascular repair. 
the patient under general anesthesia and intravenous administration of heparin sodium (50 IU/kg), the stent graft was delivered through a $22 \mathrm{~F}$ or $24 \mathrm{~F}$ sheath over a 0.035 -inch stiff guide wire and placed into the thoracic aorta.

\section{Results and Discussion}

In 5 cases the stent graft was placed without any difficulty. Two patients required covered stents (Wallgraft; Boston Scientific/Vascular, Natick, Mass), one for an iatrogenic external iliac artery rupture related to the progression of the $22 \mathrm{~F}$ sheath in this highly calcified vessel and the other for a minimal extravasation of contrast at the level of the common iliac artery after retrieval of the $24 \mathrm{~F}$ sheath. In all cases the stent grafts were successfully expanded, and the angiographic control at the end of the procedure showed complete exclusion of the aneurysm without perigraft leak. An 85-year-old woman with coronary disease died of myocardial infarction in the immediate postoperative course. There were no neurologic complications, renal failure, or other morbidity related to the endovascular procedure. The perioperative survival was $85 \%$, with no paraplegia. Spiral computed tomographic scans were performed before discharge from the hospital, at 3 and 6 months, and annually thereafter. All scans confirmed the exclusion of the aneurysm without perigraft leak. One patient died 4 months later of unrelated acute adrenal failure as a result of pneumonia. The mean follow-up period was $9.4 \pm 5.5$ months (range 5-22 months).

The main limitations on endovascular treatment of ruptured TAA are the location and the morphologic of the aneurysm, the vascular access and the availability of appropriate stent grafts in emergency. The best candidates for this technique are patients with limited disease in a quite straight portion of the thoracic aorta. Open surgical graft replacement remains the criterion standard of care for patients at low surgical risk because of the long-term durability of that type of treatment. However, our experience and recent reports ${ }^{3-5}$ suggest that endovascular treatment of ruptured thoracic aneurysm is a feasible, less invasive, and promising approach that may improve the prognosis for high-risk patients.

\section{References}

1. Moreno-Cabral CE, Miller DC, Mitchell RS, Stinson EB, Oyer PE, Jamieson SW, et al. Degenerative and atherosclerotic aneurysms of the thoracic aorta: determinants of early and late surgical outcome. J Thorac Cardiovasc Surg. 1984;88:1020-32.

2. Crawford ES, Hess KR, Cohen ES, Coselli JS, Safi HJ. Ruptured aneurysm of the descending thoracic and thoracoabdominal aorta: analysis according to size and treatment. Ann Surg. 1991;213:417-25.

3. Dake MD, Miller DC, Semba CP, Mitchell RS, Walker PJ, Liddell RP. Transluminal placement of endovascular stent-grafts for the treatment of descending thoracic aortic aneurysms. $N$ Engl J Med. 1994;331: 1729-34.

4. Dake MD, Miller DC, Mitchell RS, Semba CP, Moore KA, Sakai T. The "first generation" of endovascular stent-grafts for patients with aneurysms of the descending thoracic aorta. J Thorac Cardiovasc Surg. 1998;116:689-703.

5. Palombi M, Berardi F, Sposato S, Gargiulo M, Bochicchio O, Iaria G, et al. Endovascular treatment of a ruptured thoracic aortic aneurysm. Eur J Vasc Endovasc Surg. 2000;19:101-2. 